\section{Commentary: Taking a bite of the apple}

\author{
Thoralf M. Sundt, MD
}

A little more than 2 decades ago our specialty received a wake-up call; surgeons in practice were depressed, the job market was flat, and (likely in significant measure as a result of the former) applications and interest in our residency programs was waning. In 1997 there were, for the first time, fewer US medical graduates applying to our programs than there were positions. The response was multipronged, including both the development of an integrated 6-year path to American Board of Thoracic Surgery certification and greater attention to exposing candidates to the field. The impact of the former is a topic of considerable scrutiny, with evolving literature. Less information is available on the effect of the latter, despite a plethora of programs instituted by numerous organizations. I suspect that most of us believe that creating such opportunities is the right thing to do, especially as medical students and even general surgery residents get less and less exposure certainly to cardiac surgery and likely to high-end thoracic surgery as well. We know that this is our "pipeline" for talent. We need to give them a chance to taste the thrill of what we do. We need to make it easy for them to take a bite of the apple!

In their study in this issue of the Journal, Suarez-Pierre and colleagues ${ }^{1}$ have recognized that a potential obstacle to optimal effectiveness of such programs is simply the complexity of the options themselves. It is exciting that there are so many-but navigating them is as challenging as driving in Boston (minus the 1-way streets). SuarezPierre and colleagues ${ }^{1}$ have nicely laid out a grid (unlike the founders of Our Fair City), complete with brief descriptions of the targets of the initiatives and links to the application sites. This will be extraordinarily useful both to medical students and residents and to surgical mentors.

\footnotetext{
From the Division of Cardiac Surgery, Massachusetts General Hospital, Boston, Mass; and the Department of Surgery, Harvard Medical School, Boston, Mass. Disclosures: Author has nothing to disclose with regard to commercial support.

Received for publication Feb 10, 2020; revisions received Feb 10, 2020; accepted for publication Feb 11, 2020; available ahead of print Feb 19, 2020.

Address for reprints: Thoralf M. Sundt, MD, Division of Cardiac Surgery, Massachusetts General Hospital, 55 Fruit St, Cox 652, Boston, MA 02114 (E-mail: tsundt@ mgh.harvard.edu).

J Thorac Cardiovasc Surg 2021;161:1394

$0022-5223 / \$ 36.00$

Copyright (c) 2020 by The American Association for Thoracic Surgery

https://doi.org/10.1016/j.jtcvs.2020.02.042
}

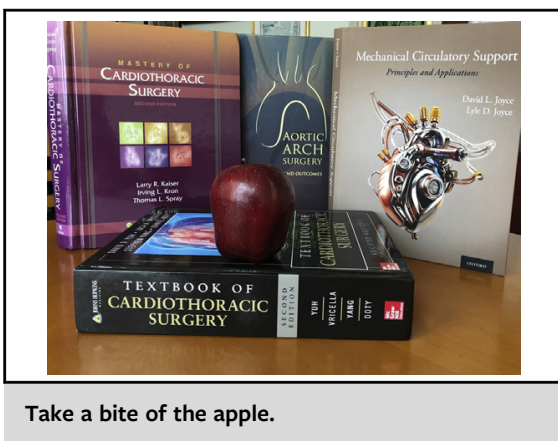

CENTRAL MESSAGE

There is a plethora of opportunities to experience our specialty. Come give it a try!

In the last 20 years, cardiothoracic surgery has been reinvigorated. It has become a more diverse field in both content and composition. The job market has opened. Less invasive interventions and new devices have expanded our capabilities and increased our treatment options at breakneck speed, challenging surgeons to keep up with our medical sister-specialists. Both racial and gender diversities are increasing as well—not fast enough to be sure-but headed in the right direction. The field is alive and exciting, and interest in our residency programs is picking up. We have taken the advice of leaders including Fred Crawford, ${ }^{2}$ Bill Baumgartner, ${ }^{3}$ Tim Gardner, ${ }^{4}$ and others, and it has served the profession well.

\section{References}

1. Suarez-Pierre A, Yang SC. Scholarships in cardiothoracic surgery-a guide for surgical trainees. J Thorac Cardiovasc Surg. 2021;161:1390-3.

2. Crawford FA Jr. Thoracic surgery education-responding to a changing environment. J Thorac Cardiovasc Surg. 2003;126:1235-42.

3. Baumgartner WA. Cardiothoracic surgery: a specialty in transition-good to great? Ann Thorac Surg. 2003; 75:1685-92.

4. Gardner TJ. Presidential address: our heritage and our future. J Thorac Cardiovasc Surg. 2002;124:649-54. 